\title{
Social Media and Retention: The Administrative Perspective at Hispanic-Serving Institutions of Higher Education
}

Amanda Muniz Galindo, Vanessa Bogran Meling, Marie-Anne Mundy \& Lori Kupczynski

Texas A\&M University-Kingsville, USA

Received: May 16, 2012 Accepted: May 24, 2012 Published: August 1, 2012

doi:10.5296/jse.v2i3.1809 URL: http://dx.doi.org/10.5296/jse.v2i3.1809

\begin{abstract}
Although the Hispanic population is the fastest growing ethnic group in the nation, they are still underrepresented in colleges and universities. Educational institutions must learn to adjust to technological innovations in order to facilitate an interactive learning environment and retain more students. Being innovative, cost-effective, and efficient while implementing retention programs at Hispanic Serving Institutions (HSIs) is highly important due to the complex nature of serving a population of first-generation, at-risk college students. Using social media at HSIs could be a cost-effective and efficient manner to communicate with and engage Hispanic students. The purpose of this qualitative study was to analyze administrative leaders' perceptions of social media and the effect it had on student retention at four south Texas Hispanic-serving institutions. The study findings offer perspectives in the areas of culture, community, communication, collaboration, and challenges that come with new technologies to increase student retention at HSIs.
\end{abstract}

Keywords: Social media, Retention in higher education, Educational administration, Hispanic students, Perceptions of social media 


\section{Introduction}

Institutions of higher education are constantly adapting to current trends in order to improve student learning, retention, recruitment, and communication. As American society conforms to an ever-changing technological era, education institutions must learn to adjust, as educational systems, in order to facilitate an interactive learning environment and retain more students.

For millions of people, the web is a social space that connects them with their friends, colleagues, family members and even total strangers. The new generation of web, or Web 2.0, as it has been labeled, supports social interaction and makes it easy for individuals to exchange information and to share their life and interests in one form or another (e.g. sharing videos in YouTube, photos in Flickr, thoughts in Blogger, and expertise in Wikipedia). (Hung \& Yuen, 2010, p. 703)

Social media is more than just technology. It is a set of collaborations and the active participation of detailed principles that exemplify our current social movement (The Paradox of Social Media, 2011). Systems of education are dealing with the pressure to retain students, to improve the first year experience for students, and to improve the overall educational environment. Technology has played a huge role in retaining students by utilizing creative and collaborative innovations, promoting a means of classroom community, and ensuring better communication within this specific population (Hung \& Yuen, 2010).

The Hispanic population is the fastest growing ethnic group in the nation, which has allowed this group of students to become a strong voice within higher education (Brown, Santiago, \& Lopez, 2003). However, even though this ethnic group is the fastest growing population, they are still underrepresented in colleges and universities (Brown et al., 2003). Hispanic students represent the largest population of first generation college students at four-year universities (Saenz, Hurtado, Barrera, Wolf, \& Yeung, 2007). Hispanic-serving institutions (HSIs) are defined as colleges, universities, or systems/districts where total Hispanic enrollment constitutes a minimum of twenty five percent (25\%) of the total enrollment (Hispanic Association of Colleges and Universities, 2011).

According to the United States Department of Education National Center for Education Statistics (2011), approximately 51\% of Hispanic students cannot complete their bachelor's degree over a six year period. Retention among Hispanic students is a great concern to HSIs due to its decreasing rates. Administrators at HSIs must be attuned to their students' needs. Being innovative, cost-effective, and efficient while implementing retention programs at a HSI is highly important due to the complex nature of serving a population of first-generation, at-risk college students. Using social media at HSIs could be a cost-effective and efficient manner to communicate with and engage Hispanic students.

\section{Objectives and Purposes}

The purpose of this qualitative study was to analyze administrative leaders' perceptions of social media and the impact it plays on student retention at institutions of higher education. There are currently fifty-six HSIs in Texas with eleven designated to south Texas (Hispanic 
Association of Colleges and Universities, 2011). The research concentrated on student retention at four out of the eleven institutions with the HSI status in south Texas, primarily due to their geographical proximity and similarities in student demographics. The HSIs targeted were public, four-year universities with a high population of first generation, Hispanic students. The study examined the various perceptions student retention administrators had towards social media and its effect on student retention at their institution.

Qualitative procedures including interviewing, recognizing themes, thematic coding, and categorizing trends were utilized to gather the results of this research. The researchers selected one student retention administrator who is responsible for leading retention efforts and implementing retention programs at their particular HSI. A total of four participants were chosen for this research. Each participant was asked a series of prescribed questions during a face to face interview in order to gain knowledge of their individual perceptions of social media effects on student retention. At the completion of the interviews, the researchers analyzed the data using qualitative methods of analysis including thematic coding. The gathered data will add to the literature on the importance of social media within institutions of higher education.

\section{Perspective}

\section{Student Retention}

Many institutions of higher education face the task of maintaining high retention levels and improving the academic success of students throughout their academic career. Despite the dramatic increase in college student enrollment, high attrition rates and low academic achievement continue to persist with a large number of students. Since retention is such an important issue within higher education, investigation into why attrition rates are so high is of the upmost importance (Geraghty, 1996).

What is needed and what is not yet available is a model of institutional action that provides guidelines for the development of effective policies and programs that institutions can reasonably employ to enhance the persistence of all their students... The development of such a model would require, among other things, not only more research on effective practice but also more research on the impact of organizational policies on those practices and in turn on student retention. (Tinto, 2006-07, pp. 6-7)

Tinto's (2006-07) model is based on the idea that institutions must put in time and research in order to retain students. When specific academic policies and technologies are used to meet the needs of the student population and environment of each institution, these resources will eventually lead to better achievement performance among students, as well as, guide them to graduation. An unsettling fact that administrators of higher education have to consider is that despite years of research on retention in higher education, the college student retention and graduation rates continue to be low among minority students, particularly among Hispanic students (Oseguera, Locks, \& Vega, 2009).

Before student retention can be specifically addressed, institutions must first create a common purpose and mission statement that requires additional support for both academic 
and student services. "Administrators and supervisors need to develop a common vocabulary, achieve strong majority buy-in for integration, and do so through various small opportunities to bring faculty and staff together in productive activities beyond "programming" and classroom models” (Frost, Strom, Downey, Schultz, \& Holland, 2010, p. 46).

Additionally, administrators must recognize the barriers that institutions of higher education face. The majority of research has demonstrated the benefits that occur when the offices of student and academic affairs create and utilize a collaborative team that promotes campus wide integration; “. . . linking formal instruction with success strategies, career and life focus, experiential application, and the act of "giving back" through service opportunities" (Frost et al., 2010, p. 47). Once this collaboration is in effect, the institution can introduce social media in order to help improve the retention of students.

\section{Social Media in Institutions of Higher Education}

Social media and social networking can be recognized as tools or supplements for informal education that support the participation of students within learning communities (Hung \& Yuen, 2010). Social networks can also allow students to take on a self-directed, independent initiative toward particular learning projects (Valjataga \& Fiedler, 2009). A combination of both interactions (collaborative and independent) may be ideal when incorporating social media and networking into learning environments within higher education. This sense of engagement will increase retention within the university (Hung \& Yuen, 2010).

Social media outlets, such as Facebook, have been shown to be useful engagement tools amongst college students by creating a space to communicate campus activities and events, thereby keeping students informed (Santovec, 2006). There are many institutions that no longer issue e-mail accounts to students. Such institutions have chosen to communicate with students through a university fan page on Facebook. Even though this may mean accepting the fact that student posts must be managed by consistently returning comments (Beck, 2010). Social media allows students to share, communicate and exchange ideas online, as well as, to build a connection within a community (Silius, Kailanto \& Tervakari, 2011). Online networking is not only a good communication venue but also an avenue where faculty or administrators can build relationships with students by taking a glimpse into their lives as posted on Facebook (Santovec, 2006).

Social media benefit students and faculty alike. Through social media students experience increased engagement and interest, thereby giving them ownership of their education. Faculty can use social media to spur creativity in the teaching of their subject (Blankenship, 2011). Approximately, four out of five professors are using some kind of social media; with about $50 \%$ of those using tools such as "videos, blogs, podcasts, and wikis in the classroom" (Parry, 2010, p. 36). Social Networking Sites (SNS) used for academic purposes have shown positive results as students interact outside of the classroom and therefore these SNSs assist in the learning process and building community (Hung \& Yuen, 2010). "Blending the real and virtual worlds," inside and outside of the classroom has shown to increase peer to peer and academic engagement, especially for first year students (McCarthy, 2010, p. 738). 
Interactive social media and community-based tools (Skype, Twitter, Facebook, YouTube, blogs, wikis, and Blackboard) are becoming more and more dominant in the classroom (Blankenship, 2011). Facebook can be used in higher education as a communication tool between the institution and students, as well as, parents, guardians, and the community. Blankenship (2011) describes five interconnected workings of social media within higher education that include: 1) attention, 2) participation, 3) collaboration, 4) network awareness, and 5) critical consumption. Social media, as well as its components, will only progress over time and as its integration into daily life increases, it must also be incorporated into education.

Higher education administrators need to realize the importance of communication among students, parents, guardians, and support services during the first year of college and thus increase proactive communication within the university environment (Daniel et al., 2009). This essential communication creates a working atmosphere that includes: student engagement, psychosocial development, retention, academic success, and communication patterns among universities, students and their parents (Daniel et al., 2009). Student involvement, communication with support services and faculty, and campus satisfaction during a student's first year of college will increase academic success and healthy adaptations. In addition, social media may also result in the possibility of new funding possibilities in a time of budget cuts (Halligan, 2010). Institutions must acknowledge the importance of communication between those involved and utilize all avenues, including social media, to create these working relationships.

The openness of online social networking comes with risks that involve personal safety and the loss of confidentiality. College administrators continue to discuss and question how to handle the unique issues posed by the potential public display of student information (Fleming, 2008). In order to mitigate the amount of necessary monitoring time needed to utilize social media, new technical solutions have been created to allow educational institutions to respond to comments and posts by flagging certain "keywords or triggers" which can then be forwarded to a support team who can then respond by posting to a user's Facebook wall (Beck, 2010, p. 15). This software may address the issues many higher education administrators have with the fast-paced student communication on social networking sites and therefore alleviate some hesitations.

\section{Research Method}

This study was conducted in the fall semester of 2011 and utilized a qualitative research method with personal interviews at four public HSI universities in south Texas. The size of the student population at each campus ranged from approximately six thousand students to nineteen thousand. The number of Hispanic students within each campus population ranged from $41 \%-93 \%$. Each university met the direct guidelines needed to be considered a HSI.

A student retention administrator from each HSI was selected based on their job title and responsibility to oversee retention efforts at their institution. The participants selected were to have common job titles, particularly administrative positions in student retention and were selected with the intention of allowing them to share their knowledge and experience on 
student retention and social media. A total of four administrators were asked for consent to participate in the study and willing to contribute to the research. Three of the administrators were Hispanic and one was Caucasian; three were female and one was male. Their years of experience in higher education varied between 11 and 27 years. Of the administrators, one had a Masters degree, two had a doctorate, and one had a terminal degree within their academic field. Collectively they have had backgrounds working with financial aid, advising, retention initiatives, enrollment management, recruiting, admissions, registration, student affairs, recreational sports, housing, and learning assistance centers.

All four administrators expressed that they used some form of social media for work purposes. Also, three out of four participants expressed that they used some form of technology for their personal use including social media and two to three types of electronic devices on a regular basis. Administrator One uses Facebook and Second Life, while Administrator Two uses Facebook as well for individual needs. Administrator Three uses Facebook and Twitter while Administrator Four expressed that she did not participate with any kind of social networking for personal reasons, but was highly familiar with electronic devices and web designing.

University administrators participated in interviews in order to give perspective that is “meaningful, knowable, and able to be made explicit” (Patton, 2002, p. 341). A standardized open-ended interview was chosen where each question was carefully worded prior to the interview in order to ensure consistency among the administrator interviews (Patton, 2002). The interview questionnaire was designed to obtain information on the administrators' perception of social media in higher education. Using a structured interview guide minimized the variation among interviewers, focused the interview with specific questions, and made it possible to conduct data analysis by simplifying the process comparing responses (Patton, 2002). The interview questionnaire was composed of five demographic questions and three student success questions.

\section{Data Collection}

The participants' contact information was obtained through university websites. Each interview was conducted on the campus of the respondent's respective institution. All four administrators were asked the previously devised series of eight questions and the interview was audio recorded in a confidential environment. The duration of the interviews was between thirty and sixty minutes for all four participants. The questions were designed to allow the participants the opportunity to express their opinions on the use of social media in efforts to improve student retention. In the interviews, the respondents led the dialogue while questions were probed throughout the conversations to keep the respondent on track.

\section{Research Question}

To examine the various perceptions leaders in higher education had towards social media and its relationship to student success at Hispanic Serving Institutions in south Texas, the following research question was selected: 


\section{Macrothink}

1. What are the perceptions of leaders in higher education on social media in relationship to student success at a south Texas Hispanic Serving Institution?

\section{Interview Questions}

The interview questions used to interview each participant began with a set of demographic questions including:

1. Can you begin by telling me about your background in education?

2. How long have you been in your current position?

3. How long have you been at this institution and what other positions have you served in?

4. What different technologies do you personally use?

5. Do you personally use social media? If so, which ones?

The interview questions used to gain perspective on social media in student success included the following:

1. Do you believe that social media serves a role in student success? If so, how? If not, why not?

2. If you do believe it serves a role, can you tell me what you as an academic leader are doing to encourage the use of social media to promote student success?

3. Looking at education today, in what other ways do you believe social media could be used to impact retention on your campus? How do you believe it can be used to promote retention?

\section{Data Analysis}

Qualitative data is used as a constant comparative model to assist the researcher in finding emergent themes (Patton, 2002). The interviews of all four participants were recorded and transcribed verbatim on a word processor. Once the interviews were transcribed, a coding system was used to find key patterns and themes in social media and retention. The data was coded on to an Excel table and listed for each respondent. After coding, thematic analysis was used to determine if there were any prevailing themes among the data. Overarching themes and trends were found which were incorporated into the results of this research study.

On the transcriptions themselves, the researchers highlighted key words and numbered them according to patterns determining if there were any prevailing themes among the participants. "When the object is to collect comparable data across respondents, then it makes no difference whether you're collecting words or numbers - cordial-but-nonjudgmental is the way to go" (Bernard, 2002, p. 219). Interpretation of the data included all four interviews and was deciphered through comparison of responses.

\section{Results}

The five major themes that were discovered from the coding were effect of culture on the use of social media, enhancement of community, increase in communication with students, 
collaboration among departments, and challenges of lack of research and confidentiality issues. Each theme had a set of specific trends that have been identified through this research.

\section{Effect of Culture on the Use of Social Media}

According to Administrator One, the location and ethnic background/culture of the campus will affect the types of technologies that are used and incorporated into higher education. It was further stated that due to certain demographics and financial restraints, not all students had access to the internet and so it was not necessarily beneficial nor a priority for certain universities to use social media. Administrator Two concurred that the particular demographic at their respective campus was "uncertain, unexposed, and very unsure” when it came to social media used in education. Administrator One has been experimenting with a social network called Second Life in its retention mentoring program, however this social network requires computers to have specific software or certain configurations that many students do not have. Many students at this particular HSI do not own computers, nor do they have internet access in their homes making the use of Second Life a challenge. Administrator Four stated that "social networking on Facebook is not helpful for student success." The research suggested that three out of the four administrators perceived that social media in higher education was not essential to retain students within the particular population and culture present at a south Texas HSI.

\section{Enhancement of Community}

Although, social media was not a tool predominately used in retention efforts at these four institutions, there was a consensus that social media could potentially build relationships. Social networking in general was perceived to be capable of building a community within the institution and amongst its students. The academic community could be enhanced when students were able to communicate with peers and faculty through social media. Additionally, Administrator Three suggested that social networking can assist in connecting first year students with alumni to enhance their institutional knowledge and future career planning. Administrator One agreed that technology as a whole, social media in particular, creates university community as it links students together as they share academic or personal information and resources with each other.

\section{Communication with Students}

When asked how technology could promote student success, a common theme found among administrators was the ease of using it to communicate with students about campus events or retention programming, thereby keeping them informed and engaged with the institution. Administrators were aware that technology can be utilized to increase productivity among their staff members and to reach students effectively and efficiently. Technology, such as computers, the internet and e-mail, have given educational administrators an effective platform for student outreach in a way that was missing before. Most administrators agreed that technology can build a stronger connection between students, faculty, and administrators.

Administrator One, in particular, suggested that social media's purpose at her institution included "communication, linking students together, forming lines of communication with 
other students, and sharing information that will make it (communication) more effective." Social media has been found to be useful with Administrator One as a communication tool: "....so far it [Facebook] has been effective in sharing dates and sharing information with our students." Administrator Two stated, "It is a place where students can complain or vent where they are not scrutinized or judged.”

Although the administrators recognized that social media was a useful platform to communicate; they also agreed that it should be partnered with face-to-face connections. Administrator Three agreed that Facebook or Twitter could be used as a communication tool with the goal of having students "come in and see a professor...or a peer mentor" to discuss grades, absences or course work that students may be struggling with. Overall, social media as a communication tool was the most common theme among all administrators.

\section{Collaboration among Departments}

Another theme that surfaced among the responses of administrators was the collaboration among departments within retention services. Kattner (2010) speaks on one university's experience with using different social media accounts for recruitment and retention by contracting a coordinator to keep up with more than thirty social media accounts including Facebook, Flickr, Twitter, YouTube, and MySpace. This institution found that having an institution wide plan increased the collaboration among departments and administrators as they shared common efforts and communicated their activities with students.

The four administrators found social media, such as Facebook, to have useful tools that allow them to receive reports on the number of likes or hits they have received on their Facebook Business page. These reports allow staff members to collaborate on peer mentoring activities, athletic events, or student activities; thereby keeping students engaged with the institution. Collaborating with other colleagues through social media resulted in communication with students becoming less daunting and more manageable for administrators.

\section{Challenges}

Through the interviews it was apparent there was a sense of hesitation with social media from most of the administrators due to the lack of research in the area. Administrator One acknowledged that "it's too early for me to say one way or another" when it comes to the effectiveness of social media in student success, whereas Administrator Four admitted that, "social networking on Facebook to me is not helpful for student success." The impact social media could make on student retention is still very unclear to many of the administrators. Many HSI administrators, such as Administrator One, have trepidations about the use of social media because of the "lack of confidentiality, security, or privacy" most social networking sites offer. Administrator One discussed the HSI's hesitation with Facebook or other social media: “....we do share a lot of pages and there might be personal information that you don't want other students to know or other people to see, so the restrictions are a main concern.”

Administrators Two and Four admitted they are presently studying internal systems, such as "Angel or Epsilen," that can be used in their retention programs to connect their students 
online rather than use the public social networks such as Facebook or Twitter. These alternate networks are being considered and implemented by Administrator Two and Four due to the built-in confidentiality protection that can meet the Family Educational Rights and Privacy Act (FERPA) that most higher education administrators are concerned about.

One respondent clearly posed the questions most administrators are still asking, "Does it have the security parameters that we need? Can we support it with the manpower in existence or with the systems we have? And how much control can we have where we are keeping our student's information safe and our information safe? Those are the things that are still preventing us from moving forward, the security issues, the safety issues, the confidentiality issues” (Administrator one, personal interview).

\section{Scholarly Significance}

This qualitative research conducted at four south Texas HSIs gave a good glimpse into an administrator's perspective on social media and its role in retention services. This study offered perspectives in the areas of culture, community, communication, collaboration, and challenges that come with new technologies. One of the perspectives that administrators at these particular HSIs shared was the impact the respective culture of an institution and its students had on implementing technology or social media into communication plans. Communication programs at HSIs that require students to have technology such as computers, smart phones, or internet access in their homes may be hindered. These results support the existing research revealing a cultural and ethnic gap in Internet access and usage among college students in the US (NTIA, 1999; Korgen, Odell, \& Schmacher, 2001). Many HSI students rely on these technology-driven communications to be offered on campus and receive communications while on campus. HSI administrators must consider these technological limitations when developing their strategic retention plans.

Another significant theme found in the research was the strong agreement on social media's role as a communication tool. Three of the four HSI administrators that participated in the study admitted over and over again that social media, such as Facebook and Twitter, is an excellent tool in communicating quickly with students. These tools allow students to evaluate programs, courses, or events at an institution which allows for immediate feedback. Communication through social media is how students are engaging with one another, faculty, and the institution. Administrators must embrace this reality.

The challenges that surfaced were noteworthy in that it must be recognized that most educators will be hesitant about adopting a new technology in education with little research. Showing that social media is effective socially may not be sufficient for the education field to adopt new integrative methods. Administrators need data and research to support the adoption or rejection of new technology. The lack of data may explain the sense of hesitation the participants expressed with regards to social media. There are also concerns about the lack of confidentiality and disclosure issues associated with many social media outlets. This perspective was shared by all the interviewed administrators. There are questions that still remain unanswered in terms of social media in higher education. Some of the questions include: Does social media have the security parameters that institutions of higher education 
need? Can HSIs support social media with existing manpower or with current technological systems? And finally, how much control can HSIs have in order to keep student and institutional information safe?

\section{Delimitations and Limitations}

This study was limited to four administrators at four HSI universities in south Texas who participated in interviews using a list of prescribed questions that included demographic questions and questions on social media. One limitation of the study was that the universities differed in population size and location which could have an effect on the use of social media at their respective campus. The larger the campus, the more revenue and resources that institution will have, allowing social media to play a larger role in education at that institution. Additionally, these themes may not be true of all HSIs and may vary with administration, student demographics, and region of the United States.

\section{Directions for Future Study}

This research leads the way toward future study in making comparisons between administration, faculty, staff, and student perceptions of social media in higher education. Interviews could be conducted using qualitative methods to gain student, staff and faculty perceptions in order to draw conclusions on social media and its effect on student retention. The results could then be compared to the current study of administrative perceptions.

\section{Conclusion}

This research was conducted in order to gain a better perspective of higher education administrators' views of social media and its direct impact on student retention. Through qualitative research at four Hispanic Serving Institutions, five common perceptions were found amongst the interviewed administrators including effect of culture on the use of social media, enhancement of community, increase in communication with students, collaboration among departments, and challenges of lack of research and confidentiality issues. Social media's effectiveness and limitations in higher education are exposed in this study which suggested a common idea that may exist at other higher education institutions similar to the four HSI's studied. The significance of social media research in higher education may impact future communication, collaboration, and success among retention administrators.

\section{References}

Beck, K. (2010). Schools and social media: Pass or fail. CRM Magazine, 14(11), 14-15.

Bernard, H.R. (2002). Interviewing: Unstructured and semistructured (pp. 203-239). In H.R. Bernard, Research Methods of Anthropology. Walnut Creek, CA: Alta Mira Press. (ROC).

Blankenship, M. (2011). How social media can and should impact higher education. Education Digest: Essential Readings Condensed for Quick Review, 76(7), 39-42.

Bonzo, J., \& Parchoma, G. (2010). The Paradox of Social Media and Higher Education Institutions. Proceedings from the seventh International Conference on Networked Learning. 
Aalborg,

Denmark.

Retrieved from http://www.networkedlearningconference.org.uk/past/nlc2010/abstracts/PDFs/Bonzo.pdf

Brown, S. R., Santiago, D., \& Lopez, E. (2003). Latinos in higher education: Today and tomorrow. Change, 35, 40-46.

Daniel, S., Lobdell, K., Springate, B., Rayome, C., Bottoni, R., Doerr, D., Saddlemire, J., \& Allen, G. (2009). Varying the frequency of intentional communication between student affairs personnel, first-year students, and their parents. NASPA Journal, 46(2), 282-300.

Fleming, D.L. (2008). Youthful indiscretions: Should colleges protect social network users from themselves and others? The New England Journal of Higher Education, 22(4), 27-29.

Frost, R., Strom, S., Downey, J., Schultz, D., \& Holland, T. (2010). Enhancing student learning with academic and student affairs collaboration. Community College Enterprise, 16(1), 37-51.

Geraghty M. (1996). More students quitting college before sophomore year, data show. The Chronicle of Higher Education, July 19, A35 - A36.

Halligan, T. (2010). The social media evolution: Online tools drive opportunities for alumni outreach, fundraising. Community College Journal, 80(4), 30-33.

Hispanic Association of Colleges \& Universities. (2011). Hispanic-serving institution definitions. Retrieved from http://www.hacu.net/hacu/HSI_Definition1.asp.

Hispanic Association of Colleges \& Universities. (2011). HACU list of Hispanic-serving institutions.

Retrieved

from

http://www.hacu.net/images/hacu/OPAI/2010\%20Fed\%20HSI\%20list.pdf.

Hung, H., \& Yuen, S. (2010). Educational use of social networking technology in higher education. Teaching in Higher Education, 15(6), 703-714.

Kattner, T. (2010). Social media in recruitment and retention: What one university has learned. Recruitment \& Retention in Higher Education, 24(8), 1-6.

Korgen, K., Odell, P., \& Schumacher, P. (2001). Internet use among college students: Are there differences by race/ethnicity? Electronic Journal of Sociology, 5(3).

McCarthy, J. (2010). Blended learning environments: Using social networking sites to enhance the first year experience. Australasian Journal of Educational Technology, 26(6), 729-740.

National Telecommunications and Information Administration (July, 1999). "Falling Through the Net: Defining the Digital Divide.” U.S. Department of Commerce. Retrieved from http://www.ntia.doc.gov/ntiahome/fttn99/contents.

Oseguera, L., Locks, A. M., Vega, I. I. (2009). Increasing Latina/o students’ baccalaureate attainment: A focus on retention. Journal of Hispanic Higher Education, 8(23), 23-48. 


\section{IIMacrothink}

Journal of Studies in Education

ISSN 2162-6952

2012, Vol. 2, No. 3

Parry, M. (2010). Most college professors use social media. Chronicle of Higher Education, 56(36), A12.

Patton, M.Q. (2002). Qualitative research \& evaluation methods. Thousand Oaks, CA: Sage Publications, Inc.

Silius, K., Kailanto, M., \& Tervakari, A-M. (2011). Evaluating the quality of social media in an educational context. International Journal of Emerging Technologies in Learning, 6(3), 505-510.

Saenz, V. B., Hurtado, S., Barrera, D., Wolf, D., \& Yeung, F. (2007). First in my family: A profile of first-generation college students at four-year institutions since 1971. Retrieved from http://www.heri.ucla.edu/PDFs/resSummary051807-FirstGen.pdf.

Santovec, M. (2006). Using online networking to engage and retain students. Recruitment \& Retention in Higher Education, 20(3), 1-5.

Tinto, V. (2006-2007). Research and practice of student retention: What next? Journal of College Student Retention, 8(1), 1-19.

U.S. Department of Education, National Center for Education Statistics, Integrated Postsecondary Education Data System (IPEDS), Spring 2003 and Spring 2009, Graduation Rates component. (NCES 2011), Indicator 23-2011.

Valjataga, T., \& Fiedler, S. (2009). Supporting students to self-direct intentional learning projects with social media. Educational Technology \& Society, 12(3), 58-69. 